\title{
CORRECTION
}

\section{Correction to: Emergence of deep convection in the Arctic Ocean under a warming climate}

\author{
Camille Lique $^{1} \mathbb{D} \cdot$ Helen L. Johnson $^{2} \cdot$ Yves Plancherel $^{2}$
}

Published online: 18 November 2017

(c) Springer-Verlag GmbH Germany, part of Springer Nature 2017

\section{Correction to: Clim Dyn}

https://doi.org/10.1007/s00382-017-3849-9

In the original article, Figures 3, 4 and 5 are the same one (a duplication of Figure 4).

The corrected version of Figures 3 and 5 is given below. The original article was corrected.

The original article can be found online at https://doi. org/10.1007/s00382-017-3849-9.

\section{Camille Lique}

Camille.Lique@ifremer.fr

1 Laboratoire d'Océanographie Physique et Spatiale, UMR6523, CNRS-Ifremer-UBO-IRD, Brest, France

2 Department of Earth Sciences, University of Oxford, Oxford, UK 
Fig. 3 Mean March and September sea surface temperature (SST, in ${ }^{\circ} \mathrm{C}$ ) for the $C T R L$ and the $4 \times \mathrm{CO}_{2}$ runs and the difference between the two runs. For the bottom raw, black hatching indicates areas where the difference between the two runs is not significant. The red contour corresponds to the location of the sea ice edge (defined as the $15 \%$ concentration contour), and the black contour on the bottom panels shows the $500 \mathrm{~m}$ isobath
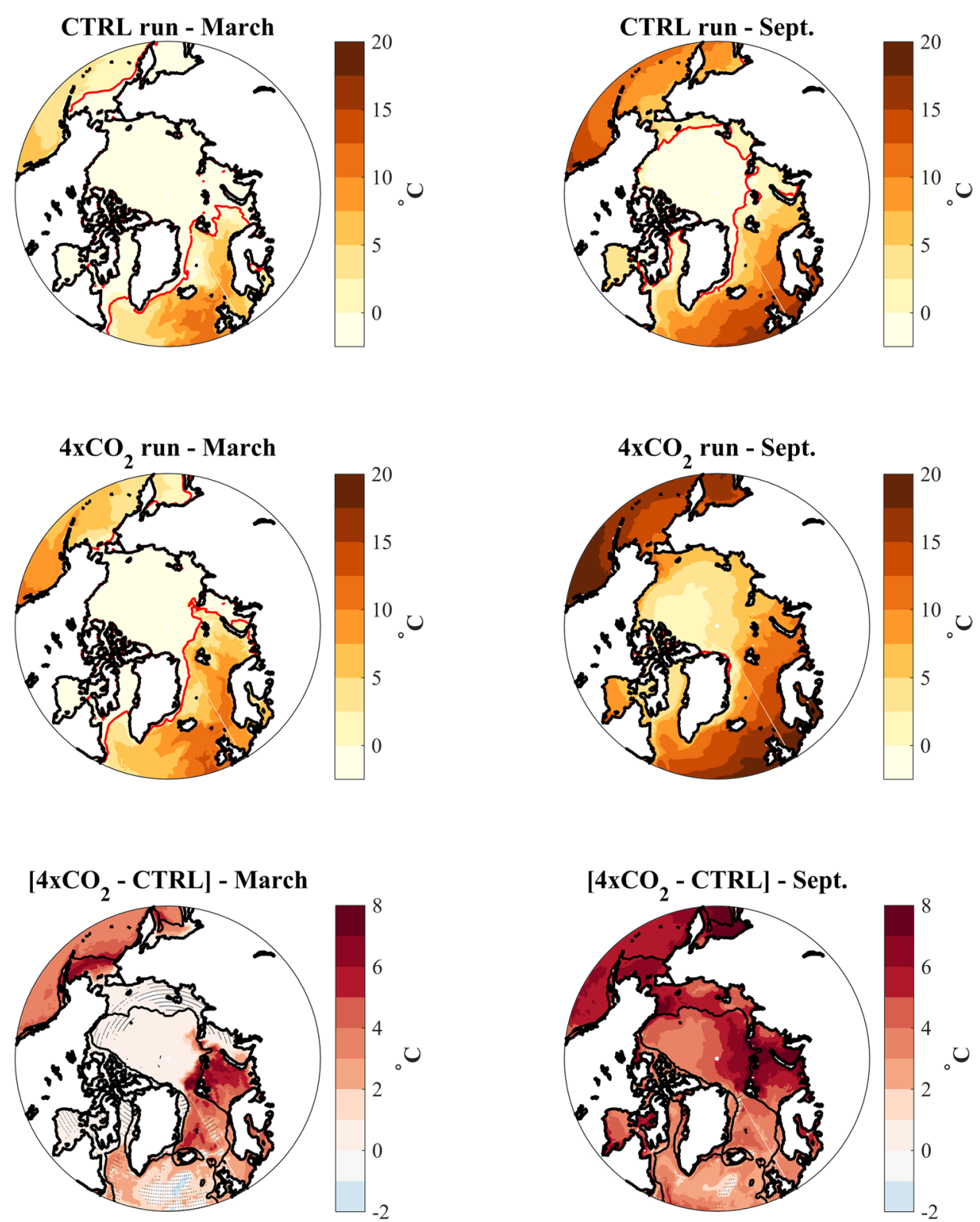
Fig. 5 Mean March and September sea surface potential density $\left(\sigma\right.$, in $\left.\mathrm{kg} / \mathrm{m}^{3}\right)$ for the $C T R L$ and the $4 \times \mathrm{CO}_{2}$ runs and the difference between the two runs. For the bottom raw, black hatching indicates areas where the difference between the two runs is not significant. The red contour corresponds to the location of the sea ice edge (defined as the $15 \%$ concentration contour), and the black contour on the bottom panels shows the $500 \mathrm{~m}$ isobath
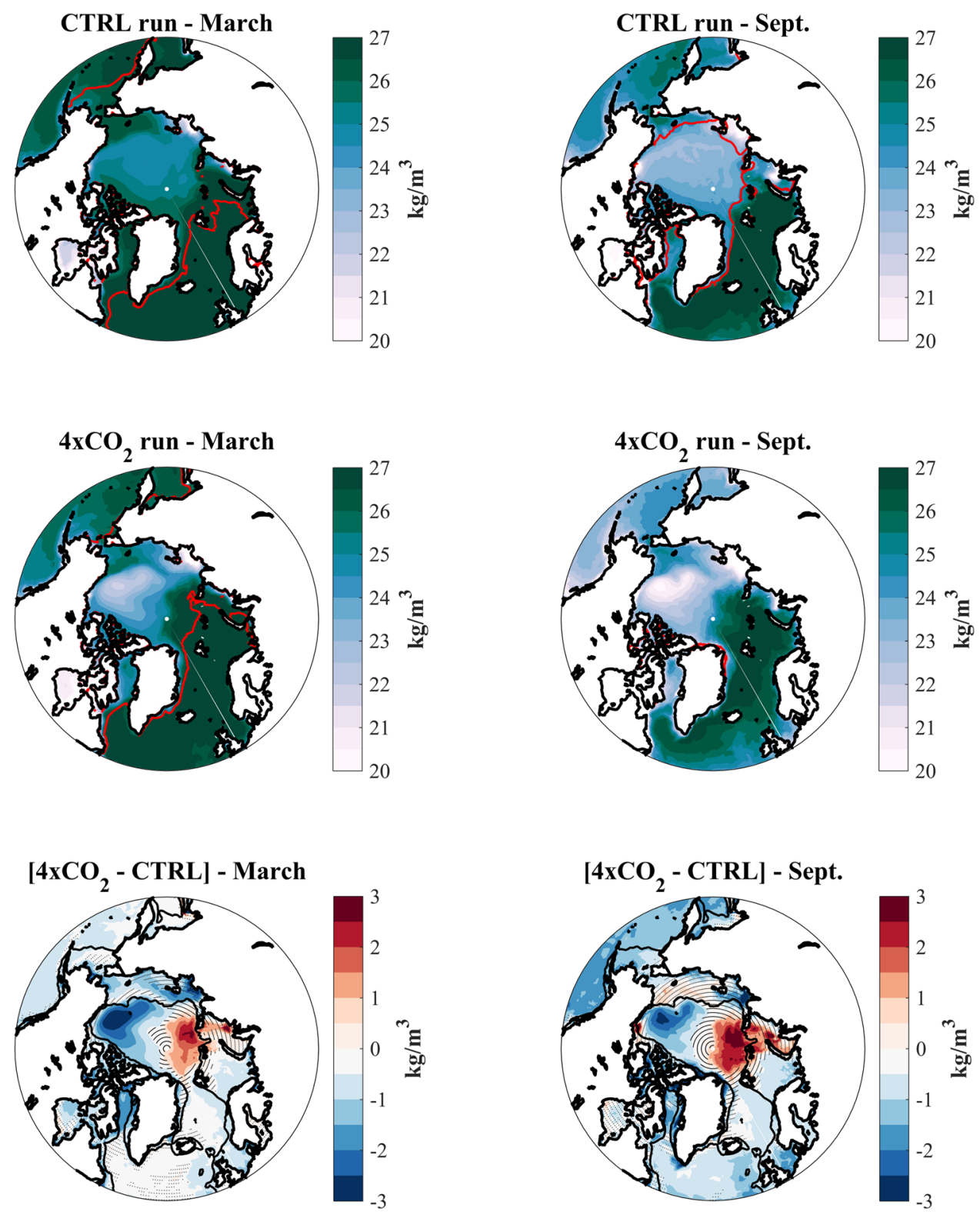

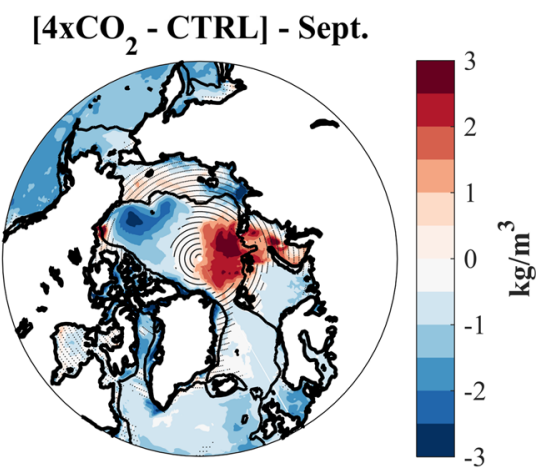

